\title{
The study of emotional processes in communication: I. Measuring emotionalization in everyday face-to-face communicative interaction
}

\author{
MARIE-LOUISE KÄSERMANN, ANDREAS ALTORFER, KLAUS FOPPA, \\ STEFAN JOSSEN, and HEINRICH ZIMMERMANN \\ University of Berm, Berm, Switzerland
}

\begin{abstract}
The drawbacks of traditional research into emotional processes have led us to develop a set of methodologies for investigating them in everyday face-to-face communication. The conceptual basis of these procedures is a model of the eliciting conditions of emotional processes as well as a conceptualization of the emotional processes themselves. On the basis of the assumption of conversation as a rule-governed process, one can describe its default temporal, formal, and functional features, for which we use the MAS EDIT and SEQ programs, and the minimal model of communicative exchange, respectively. Violations of these default rules can be identified as unexpected/temporally unpredictable events eliciting emotionalization. The nature of emotionalization is determined by the psychological principle of "standard and deviation." Its investigation under natural conditions requires the following: A noninvasive method of data acquisition (including procedures for rejecting faulty or missing values), measurement (high-resolution recording of physiological, psychomotor, and vocal variables), and the (nonstatistical) construction of an inventory or "relevant effects" (contrastive and template analysis). Finally, we depict three routes of investigating time courses of activation changes as dependent and independent variables and as a target of modification and reflection.
\end{abstract}

\section{The Problem of Investigating Emotional Processes in Social and Communicative Interaction}

Emotional processes, including unspecific negative distress and positive eustress, form a pervasive and important aspect of everyday life. Most of these processes may be elicited by features of social and communicative contexts (e.g., Scherer \& Tannenbaum, 1986; Scherer, Wallbott, Matsumoto, \& Kudoh, 1988), and their ongoing course and outcome are critical for healthy individuals' local functioning and global well-being. This can be inferred, for instance, from psychoneuroimmunological evidence (e.g., Glaser et al., 1987; Kiecolt-Glaser \& Glaser, 1991). But it also holds true for psychosomatic phenomena (Pennebaker, Hughes, \& O'Heeron, 1987) and some psychopathological phenomena. For example, schizophrenic individuals' rate of relapse into acute phases of illness p peitly depends on characteristics of the familial style of cynversation (Doane, West, Goldstein, Rodnick, \& Jones, 1981; Vaughn \& Leff, 1976). There, relatives' emotic,nally overinvolved or hostile remarks function as stressors. Unfavorably combined and occurring at a critical frequency, they form the communicative antecedents

Parts of this research were funded by Grants $1114-043635.95 / 1$ and 1113-051050.97/1 from the Swiss National Science Foundation. The authors thank Nicole Gilgen for her assistance with transcription, MAS EDIT, and SEQ analyses. Correspondence should be addressed to M.-L. Käsermann, University of Bern, Psychiatric Institutions, Department of Psychiatric Neurophysiology, Bolligenstrasse 111, CH-3000 Bern 60, Switzerland (e-mail: mkaesermann@puk.unibe.ch). of distress in the schizophrenic index person. Furthermore, the way in which the schizophrenic and/or his/her partner cope with such a stress reaction may be instrumental to aggravating or to ameliorating a given condition (Käsermann, Altorfer, \& Jossen, 1998). The same, although perhaps in a less obvious fashion, holds true for communicative relationships between healthy interactants (e.g., Käsermann, 1995; Käsermann \& Altorfer, 1991; Levenson \& Gottman, 1985).

It is uncontroversial then that features of the actual social and communicative exchange affect the optimal (emotional) functioning of an individual; therefore, they should be scrutinized closely. However, there is one very intriguing problem with most research into human emotion (Käsermann, 1995): Analyses of everyday emotional processes in real time are rare in psychology (for exceptions, see Epstein \& Fenz, 1965, and Schedlowski et al., 1993). Furthermore, as a rule, the direct measures of, for example, autonomic activity, that they use do not represent the course of emotional processes, since it is tied to specific features of social or communicative interaction. Rather, they report average-based indices for various types of situations (e.g., Gottman \& Levenson, 1992; Levenson, Carstensen, \& Gottmann, 1994; Levenson \& Gottman, 1983, 1985). Other approaches mostly use indirect measures, allowing only for inferences about features of the relevant situations. Evidence in schizophrenics cited above, for instance, stems from correlation studies concerned with the co-occurrence between indirectly identified stressors (assessed with the Camberwell Family In- 
ventory; Leff \& Vaughn, 1985) and outcome data (especially the rate of relapse). Furthermore, there exist many studies of ongoing stress or startle reactions; however, these are experimentally induced under laboratory (i.e., artificial) conditions by nonsocial (e.g., noise) antecedents (e.g., Lang, Bradley, \& Cuthbert, 1990). Finally, most of today's research is concerned with (everyday) distinct or basic emotions, such as fear, disgust, anger, or joy (Scherer, 1990). These are conceived of as differing from each other with regard to their eliciting conditions (Scherer, 1988) and with regard to specific patterns of their experiential (e.g., physiological), expressive (e.g., vocal, physiognomic; e.g., Ekman, Friesen, \& Ellsworth, 1972), or motivational-action components. However, because of the methodological assumption of an isomorphism between these distinct entities and a linguistic inventory of labels for them, there seems to be no need to investigate them when they occur spontaneously. Rather, researchers, by using a specific vocabulary of emotions to instruct subjects to remember past emotional experiences, as a rule, are tapping only emotional reminiscences (e.g., Levenson, Carstensen, Friesen, \& Ekman, 1991).

Of course, the flaws of these approaches to emotional processes have not gone unnoticed. In fact, several methods to overcome them and to assess the relevant events when they take place have been developed. For instance, Gottman and collaborators use a method of having subjects continuously rate their effect by setting a dial during self-confrontation with a videotaped past conversational situation (e.g. Levenson \& Gottman, 1985). Even nearer to the relevant site are the experience sampling method (Csikszentmihalyi \& Csikszentmihalyi, 1988) and the COMES (Reicherts \& Perrez, 1990). Both of these use electronic devices to alert individuals into noticing the occurrence and the quality of an ongoing emotional process. However, it is obvious that data generated in this manner hardly register the emotional process proper but an individual's comments on an emotional event mediated by her/his reflections on it. To make things even more blatant, these "meta-emotional" statements are often controlled by researchers' (electronically presented) questions, which nicely fit her/his respective theory of emotion. There is, to our knowledge, just one endeavor, the CARMEN machine (Hughes, Uhlmann, \& Pennebaker, 1994; Pennebaker \& Uhlmann, 1994), that registers the direct link between word usage and autonomic (emotional) activity (as opposed to constructing a post hoc connection like Gottman and collaborators). However, the application of this device is restricted to the (nonsocial) situation of an individual's writing essays (e.g., about traumatic experiences) on a computer.

In summary, this goes to show that whatever is known about emotions hardly addresses the problem of tapping the course of ongoing emotional processes in everyday situations in a principled way. Therefore, mechanisms underlying the relationship between features of social and communicative exchange and emotional processes are not yet well understood (Kiecolt-Glaser, 1992; Kiecolt-Glaser $\&$ Glaser, 1988). There are only a few analyses that have addressed the problem of the exact mechanisms underlying the effects that the relationship may have on an individual's actual functioning and long-term well-being (e.g., Pennebaker et al., 1987). The question then is, What makes it so hard to investigate emotional processes while they are taking place, and what should be changed in order to overcome this difficulty?

The first part of our answer concerns the nature of emotional processes occurring in natural situations. From our experience as participants in and researchers of communicative interaction (e.g., Käsermann, 1995), we are convinced that what characterizes these situations most of the time is not distinct emotions (e.g., joy, fear) but small-scale fluctuations of mood (emotionalizations), which express themselves in subtle (e.g., physiological, vocal, and/or psychomotor) changes. This claim concerning unspecific positive and negative emotionalizations can be assessed very well introspectively. Furthermore, analyses of emotional processes in relationships with children (e.g., Denham \& Couchoud, 1990a, 1990b; Eisenberg et al., 1996; Fabes, Eisenberg, Karbon, Troyer, \& Switzer, 1994), clients (e.g., Käsermann, 1995, pp. 204 207), or spouses' (e.g., Levenson \& Gottman, 1985) show that, in these contexts, emotional processes often elude being named as distinct emotion. Considering that communicative exchange is a fast-moving joint action in time, the elusive character of emotionalization does not come as a surprise. It is quite possible that, in the reflection of, say, a parent or therapist or in the retrospect of a client, such episodes may be labeled as distinct emotion; however, when they occur, they are not.

This leads to the second part of our answer: how to be able to investigate actual emotional processes. Most clearly, emotionalization defeats being reactualized by emotion words. So you (or your recording equipment) have to be there when emotionalization spontaneously happens. At the same time, you need to record the essential process in an unobtrusive way. Furthermore, for your subsequent exploratory and explanatory analyses, you need to know where to expect the occurrence of emotionalization in your records. To grasp these requirements, we assume that emotionalizations are elicited by, for example, unexpected or unpredictable (and negatively or positively evaluated) events. This point is taken up in the next section, in which we describe the conceptual and methodological prerequisites of our endeavor to identify elicitors of emotionalization. They are interdisciplinary in being based on psychology, physiology, linguistics, and computer science. Problems connected with the independent identification of emotionalization, the unobtrusive recording, highly resolving measurement, and systematic analyses of data from nonlaboratory situations are later discussed. Finally, on the background of 
this framework, we depict routes of investigating emotionalization, its antecedents, and its consequences in everyday situations.

\section{A Minimal Model of Communicative Exchange as a Framework for the Detection of Emotionalization in Everyday Interactions}

A central problem in investigating naturally occurring emotional processes is to predict them and observe them when and where they may occur. One way of tackling this task is to gather knowledge about conditions eliciting emotional processes. As already mentioned, social and communicative contexts are very likely to contain potent elicitors of emotionalization.' Theoretically (e.g., Berscheid, 1983; Mandler, 1975; Scherer, 1988, 1990), there is consensus that such elicitors reside in the experience of novel or unexpected events. Empirically, the emotionalizing effect of this type of experience has already been demonstrated (Garfinkel, 1963) and experimentally induced (McCann \& Higgins, 1988). However, the problem of discovering elicitors that are meaningful for individuals in actual social or communicative exchange is as yet unresolved. To fill this gap, we propose a set of principles that enables the structuring of natural conversation in order to detect potential elicitors of emotionalization. The basic idea guiding our action is the assumption that conversation is a rule-governed event in which rulecongruent behavior is the expected case. Deviation from or violation of such rules then are the prime candidates of the unexpected events, which could be the elicitors of emotionalization that we are looking for.

The formal structure of conversation. In order to handle everyday conversation without reducing its real variability through an experimenter's intervention, one has to find a means of structuring an adequate record of it (an audiotape and/or videotape) without drastically changing the event itself. To achieve this task, it is helpful to acknowledge the vast body of linguistic evidence provided by conversation analysts (e.g., Garfinkel, 1967;
Goffman, 1981; Heritage, 1989), who describe communicative exchange as rule-governed behavior. On a first and very simple level, conversation is a temporally organized sequence of speaking turns distributed between two or more participants. In our research, these simple temporal features of conversation are determined by the application of MAS EDIT (Figure 1).

MAS EDIT is a program applied to a digitized audio record. It works with a trigger, which enables it to detect the on-off pattern of sound. Subsequently, the resulting automatic solution is edited manually to resolve problems of detecting simultaneous speech. Both steps together yield an exact time-coordinated on-off pattern of speech of each participant.

Ideally, in a conversation, one participant is in the speaker's role while the other is listening, and the change of roles is dependent on the participants' adherence to a few rules of (self-) selecting the next speaker (Sacks, Schegloff, \& Jefferson, 1974). In reality (e.g., Tannen, 1981; see also, above, the description of MAS EDIT), the matter is less clear-cut. In addition to Speaker A's (or B's) speaking and Listener B's (or A's) complementarily keeping silent or giving back channel signals (e.g., $/ \mathrm{hmm} /$, nodding), it is possible, at any point in a conversation, for both participants to speak simultaneously or to keep silent. Partly, the meaning of any of these four states of communicative exchange depends on the context of their occurrence. In a smooth-running dyadic conversation, the state of "A speaking" changes most probably to "B speaking." But, if B does not take a turn, the system changes into "both keep silent," and this is only one of several possible deviations from an ideally rule-governed pattern of turn taking. The cumbersome business of identifying the diverse possible states and their context of occurrence can be supported by the application of SEQ (Table 1).

SEQ processes the output data of MAS EDIT in determining the duration of (1) speaking turns of each participant, (2) speech-free times between the turns of two speakers ("dialogue pauses") and within each speaker's

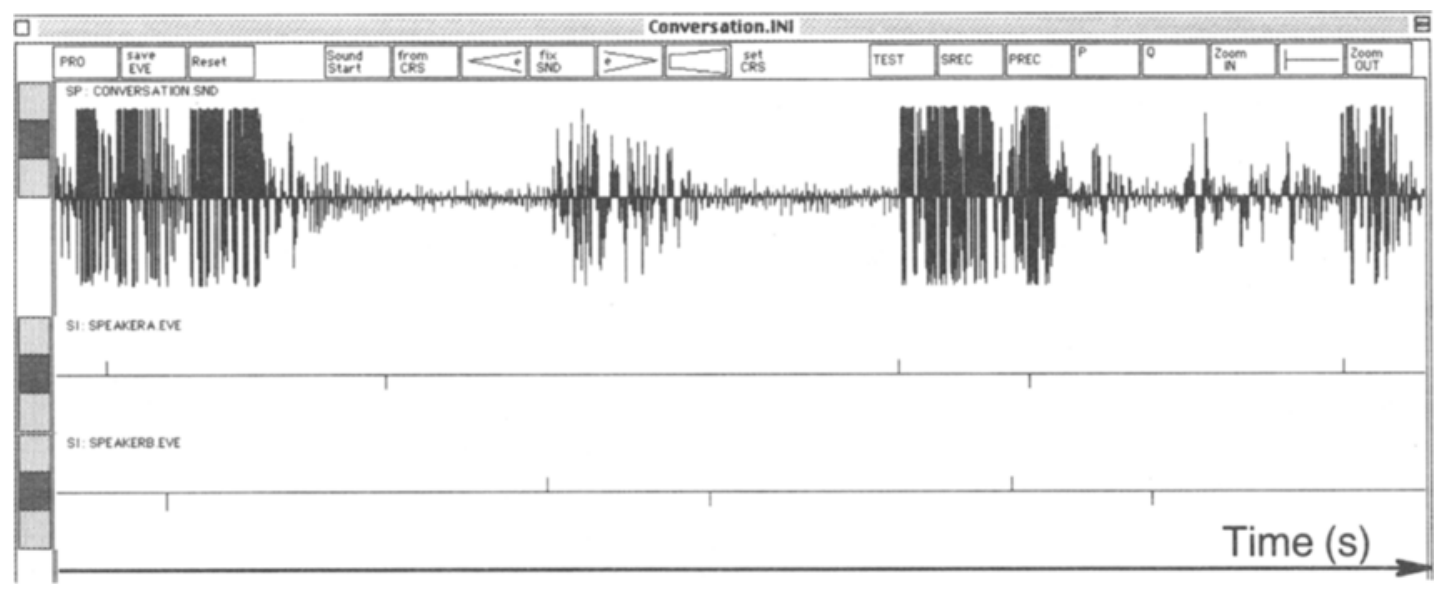

Figure 1. MAS EDIT: Identification of on $\rightarrow$ off pattern of sound (on = mark ascending; off = mark descending from the time axis). 
Table 1

SEQ: Assignment of Duration and Classification of States of Conversation

\begin{tabular}{lccr}
\hline Codes & Start of Event & End of Event & Duration \\
\hline A & 28.50 & 35.38 & 6.88 \\
ASSB & 31.10 & 35.38 & 4.28 \\
B & 31.10 & 55.76 & 24.66 \\
BSSA & 42.23 & 55.76 & 13.53 \\
A & 42.23 & 110.16 & 67.93 \\
ASSA & 62.97 & 69.15 & 6.18 \\
ASSA & 83.11 & 99.02 & 15.91 \\
ASSB & 104.87 & 110.16 & 5.29 \\
B & 104.87 & 134.59 & 29.72 \\
BSSA & 125.77 & 134.59 & 8.82 \\
A & 125.77 & 165.69 & 39.92 \\
ASSA & 142.57 & 143.07 & 0.50 \\
ASSA & 152.90 & 161.44 & 8.54 \\
DPB & 165.69 & 166.55 & 0.86 \\
B & 166.55 & 199.62 & 33.07 \\
BSSB & 176.41 & 176.75 & 0.34 \\
A & 176.41 & 176.75 & 0.34 \\
BSSA & 182.27 & 199.62 & 17.35 \\
A & 182.27 & 230.23 & 47.96 \\
ASSA & 207.12 & 222.92 & 15.80 \\
DPB & 230.23 & 230.91 & 0.68 \\
B & 230.91 & 265.56 & 34.65 \\
BSSB & 239.59 & 250.95 & 11.36 \\
BSSA & 256.90 & 265.56 & 8.66 \\
A & 256.90 & 276.36 & 19.46 \\
ASSB & 271.81 & 276.36 & 4.55 \\
B & 271.81 & 283.99 & 12.18 \\
DPA & 283.99 & 285.34 & 1.35 \\
A & 285.34 & 295.70 & 10.36 \\
ASSB & 292.36 & 295.70 & 3.34 \\
\hline
\end{tabular}

Note-Values are given in seconds. Codes are as follows: A, A speaks; ASSB, B speaks simultaneously with A and takes over the speaker's role (and vice versa for BSSA); ASSA, B speaks simultaneously with $A$ but does not succeed in taking over the speaker's role (and vice versa for BSSB); DPB, after A speaks and a pause, B takes over the speaker's role (and vice versa for DPA).

turn ("monologue pauses"), and (3) time spent in simultaneous speech.

The minimal duration of a speech-free time critical for its identification as a "pause" is a variable that can be set by the researcher. Furthermore, SEQ assigns codes to distinct classes of sequences of states: for example, code DPB to [(context "A speaks")-(state "both silent")- (context "B speaks")]; code DPA to [(context "B speaks")--(state "both silent")-(context "A speaks")].

MAS EDIT and SEQ do a great deal in formally structuring any communicative exchange. However, they do not do everything necessary for the ultimate goal of recognizing the occurrence of violations as potential elicitors of emotionalization. Consider the SEQ sequence of categories [(context "A speaks")-(state "both silent")(context "A speaks")]: "Both silent" can occur because $A$ announces that he/she has to think before completing his/her utterance. But it can also occur because B does not take over the speaker's role offered by $A$. In the former case, B's not speaking is expected for A; however, in the latter, it is not. Thus, SEQ categorizes as formally equivalent sequences, which differ functionally. Because emotionalization in conversation, in our view, has to do with experiencing unexpected events, it is necessary to develop some additional organizing principles by which this distinction can be achieved.

The functional structure of conversation. Conversation is not only a temporally ordered sequence of speaking turns contributed by two or more participants. If this were the case, one would not be able to distinguish between temporally organized but unrelated monologues (à la Beckett) and real dialogue (Foppa, 1990). Rather, the central feature of conversation is the exchange of meaning: A speaker addresses the listener with a message, and the latter in turn interprets the speaker's behavior (verbal or otherwise) as an actually meaningful contribution. That is not to say that an interpretation of Speaker A's (verbal) behavior is always possible, nor that B's interpretations are always congruent with what Speaker A wanted to say. Rather, this means quite trivially only that conversation is the (ultimately successful or unsuccessful) endeavor to mutually exchange meaningful behavior.

In scientific approaches, the phenomenon of conversationally making meaning is variously conceptualized as the production of mutual understanding (e.g., Herrmann \& Grabowski, 1994), as establishing coherence (Heydrick, Neubauer, Petöfi, \& Sözer, 1989), or as acting cooperatively (Grice, 1975). But to apply these concepts to a real-life communicative exchange is notoriously difficult, because they often describe the competence of an idealized speaker-listener. Even with an inventory of specifically coherent adjacency pairs (e.g., questionanswer; greeting-greeting back; invitation-acceptance; see Schegloff \& Sacks, 1973), the problem cannot be solved. In most cases, determining whether any behavior is a (rule-matching) coherent or (rule-violating) incoherent contribution to conversation is not possible, because most of the observable sequences cannot be identified in term of such pairs.

In our opinion (Käsermann, 1995), the problem with these approaches is twofold. First, each of them proceeds from a positive-inclusive (as opposed to a negativeexclusive) notion of meaning. ${ }^{2}$ Second, they exclusively model the conditions of a successful exchange of elaborated meaning. There are several reasons why these conceptualizations are not useful in determining the functional relations holding between utterances in a eal conversation. In actuality, an addressee's coherent reple in everyday conversation can hardly be construed as beirg dependent on a precise understanding of what a sender intended to mean. This is so because a sender often does not know in any detail what he/she wants to say, and the addressee, therefore, has to cope with imprecise, elliptic, and allusive utterances. However, the sender luckily is also tolerant of the meaning the addressee extracts from such a vague utterance; as long as it does not contain some- 
thing he/she definitively did not intend to say, the addressee's possibly vague and imprecise interpretation is not rejected by the sender. This implies that an utterance should not be conceived of as transporting an elaborated or positive-inclusive meaning, which has to be exactly reconstructed for a reply to be coherent. Rather, it can be viewed as a negative exclusive instruction about what definitively should not be understood (see also Miller, 1999 , p. 14, on the determination of meaning by instruction). That is, only if an addressee understands something that was definitively not meant by the speaker does the latter experience it as unexpected and may then intervene. Seen from this angle, a model describing real conversations should be able to account not only for the case of understanding but much more so for the case of variously unsuccessful exchanges.

These ideas can be expressed more formally with the help of a minimal model of communicative exchange that defines the functional relations holding between any sequence of three consecutive utterances from any 2 participants, A and B (Figure 2a).
Seen from the perspective of Participant $A$, the interpretation of Al implied in $\mathrm{B} 1$ can be evaluated by $\mathrm{A}$; if in it there is an unexpected non- or misunderstanding (i.e., if it contains something A definitively did not mean to say), there is a corrective rejection in A2. ${ }^{3}$

As it stands, the model does not yet specify the conditions under which necessary corrections do not occur in A2. This, however, is not important for the problem of the identification of elicitors of emotionalization. If any surprising or undesired B1 interpretation occurs, it creates an unexpected deviation from A's expectations concerning a smooth-running exchange. Independently of whether such a discrepancy is ultimately corrected, its mere occurrence is recognized by its emotionalizing effect (Figure $2 b$ ).

Indeed, there is evidence (e.g., Käsermann \& Altorfer, $1989,1991)$ that the recognition of such deviations forms important eliciting antecedents of emotionalization. Naturally, it is not only unexpected events but also expected (though as to the time of their occurrence unpredictable) events or undesired events that probably elicit emotion-

(a)

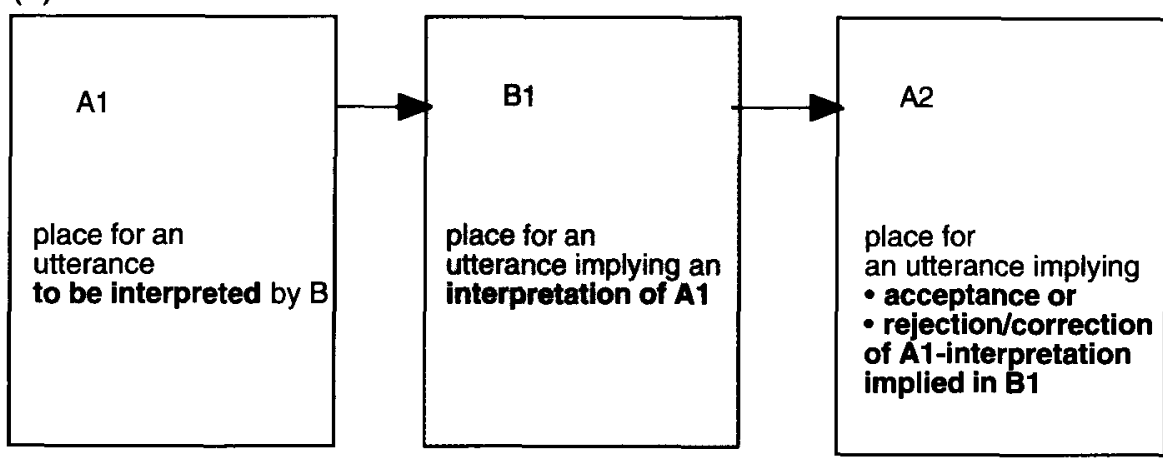

(b)

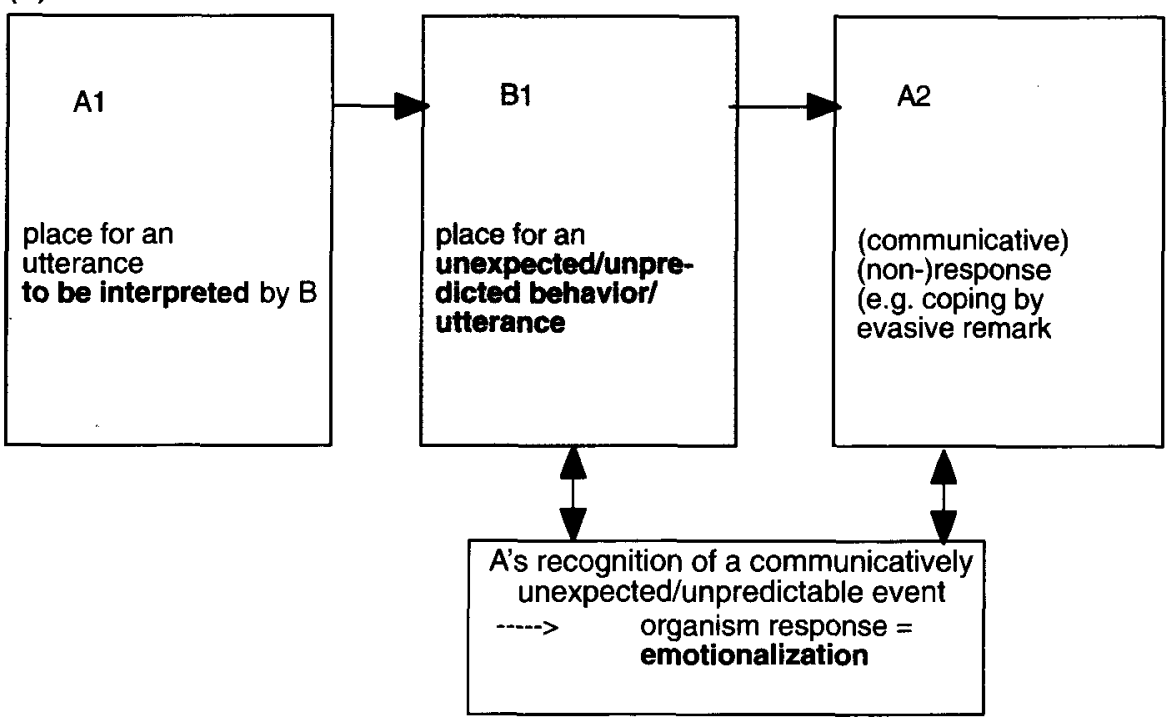

Figure 2. Minimal model of communicative exchange: (a) basic functional relations between three consecutive utterances; (b) unexpected/undesired/unpredictable events eliciting emotionalization. 
alization. However, up to now, we have not investigated the potentially emotionalizing force of the latter types of repetitive elicitors. Furthermore, it is certainly not communicative events alone but also internal (e.g., suddenly remembering something) and external events (e.g., the breakdown of electric supply) that may have an emotionalizing effect. But these eliciting conditions are not primarily part of the communicative exchange and, therefore, are not a primary target of our work.

There are in principle two ways for a researcher to decide, independently of any concomitant organism reaction, whether any B1 creates a deviation from A's standard expectations. The first one is already implied in the functional relations of the basic unit: Whenever there is an $\mathrm{A} 2$ rejection or correction of $\mathrm{Bl}$, emotionalization should have occurred somewhere between the onset of B1 and A2. This way of identifying places of emotionalization seems quite straightforward, but it is not. That is so because, first, as already stated, necessary corrections do not always occur, and, second, because it is a nontrivial task to define and identify corrections (Käsermann, 1989). The second way is to make explicit what kind of B behavior could create an unexpected event. Here, we rely on knowledge from linguistic conversation analysis that informs us about rules or regularities in conversation. This body of knowledge allows for complementarily formulating the kind of behavior that constitutes deviations from or violations of these rules and therefore permits the listing of potential elicitors of emotionalization.

The model we propose as a framework for the investigation of emotionalization in everyday situations lays claim to being generally applicable. That is to say, we do not restrict ourselves to address only negatively tuned emotionalization. Rather, our model encompasses in principle unspecific as well as negative and positive emotionalizations. In our research, however, we have not yet investigated the emotionalizing effect of positively tuned events but have concentrated on intrusiveness (Käsermann \& Altorfer, 1989), silence and interruption (Käsermann \& Altorfer, 1991, 1994), and other more subtle communicative violations (Käsermann, Altorfer, \& Jossen, 1997). Nevertheless, there are two important things we learned from these studies: In the majority of cases, conversational behavior deviating from standard expectations systematically elicits organism emotionalization. However, there are always situations in which a specific unexpected event does not activate its receiver, and there are almost always additional features of the situation that make it plausible why that event did not have an emotionalizing effect. ${ }^{4}$ These findings allow us to draw two conclusions: First, it is not the event as such, which should be conceived of as an objective stressor, as is done within the research cited above (e.g., Vaughn \& Leff, 1976; Doane et al., 1981). Rather, an unexpected event has to be treated as only potentially critical. This means that an individual can (under specific additional conditions), but need not (in the absence of them), interpret it as a stressor. Second, this implies that interpreting a communicatively critical event as a stressor not only requires the event to occur but systematically takes place under additional (but as yet unknown) conditions. Therefore, these additional conditions (e.g., time and place of the occurrence of a violation, the status of the violator, etc.) should not be controlled like disturbance variables in a traditional experimental setting. Rather, they should be resolved by exploratory research strategies (cf. the description of contrastive analysis below).

\section{The Conceptualization of Emotionalization as a Deviation From Standard Activation, Its Registration, Measurement and Analysis}

The standard-deviation principle and the independent identification of emotionalization. So far, we have discussed aspects of the psychological environment and their role as potential elicitors of emotionalization. Being able to identify their occurrence in (the transcript of) a given conversation permits the selection of the exact point in time where to predict the occurrence of an emotionalization. However, in order to avoid circular reasoning as yet unknown antecedents (elicitors) and consequences of (ways of coping with) emotionalization, its nature (e.g., physiologically registered) has to be determined independent from the (potential) conditions and effects of its occurrence. Specifically, in order to identify a stress reaction, one cannot rely on the identification of the antecedent occurrence of potentially eliciting stressors. Rather, one has to determine the occurrence of an individual's stress reaction on the basis of features (e.g., physiological, vocal, psychomotor) that have been assessed as being critical for it.

We base the discovery of such critical features on the assumption of a (psychological) principle that is applicable to a wide variety of problems, such as perception and attention (Prinz, 1990) and learning and memory (Foppa, 1999). This principle states that unexpected or unpredictable stimuli are conspicuous (although not necessarily conscious) to an individual insofar as they create (perceived or experienced) deviations from a default or standard course of ongoing functioning. On this general background, it is consistent to conceptualize emotionalization itself as that relevant organism (e.g., physiological, vocal, psychomotor) event that can be perceived as a deviation from a standard or neutral course of activation. ${ }^{5}$ Provided such standard courses can be found, our conceptualization of emotionalization as a critical deviation makes it possible to identify instances of its occurrence independent of its eliciting conditions. ${ }^{6}$

In discussing standards, it should be noted that we do not imply any normative claim. Standard may become everything that is default value under some conditions.? The course of activation during relaxation in schizophrenics may look different from the course of activation during relaxation in healthy individuals (or in smokers relative to nonsmokers). Seen from this angle, a standard of one individual (or group of individuals) may be treated as a deviation relative to another person's (or group's) standard pattern, or vice versa, depending on a given problem to be solved. But, in pursuing the question of whether a 
specific individual (e.g., a schizophrenic) is emotionalized by a specific communicative event, her/his own course of activation during topically neutral or relaxation periods (see also note 7) serves as the most adequate standard.

In our work, the identification of emotionalization as a deviation from a standard course of activation is implemented by various procedures. The basic idea is, first, to determine the invariant features of courses of activation during neutral or standard episodes (e.g., of relaxation). This pattern is construed as an individual-specific baseline with which, second, critical courses (e.g., of activation concomitant with the occurrence of a communicative violation) are compared and invariant features of deviation are extracted (e.g., Käsermann \& Altorfer, 1989; see description of contrastive analysis, later in this paper). An interesting semiautomatic implementation of the standard-deviation principle in finding emotionalization is template analysis (TA; Käsermann, 1998; see also Jossen et al., 2000). Simplifying the observationbased construction and rater-dependent validation of invariant categories of standard courses and deviations (e.g., Käsermann \& Altorfer, 1989), TA supports the fast selection of single standard courses of activation (or head movements; see Altorfer et al., 2000) in vast amounts of data. On the basis of a correlation function, it then provides for their program-based comparison with courses of activation at selected and possibly critical points in time. However, both types of processing data, according to the standard-deviation principle, allow for the necessary cross-validation within sets of data. ${ }^{8}$

The registration, measurement, and analysis of organism variables as indicators of emotionalization. Up to now, we have elaborated on a pragmatically feasible conceptualization of emotionalization. However, the realization of a standard-deviation processing of courses of activation rests on a number of theoretical and methodological prerequisites. In what follows, we deal with the problem of how to realize our concepts empirically through registering parameters of activation in natural situations and transforming them from raw data to measured units of meaningful observation.

Securing potentially meaningful variation without restricting naturalness of situation. The first point is to register indicators of emotionalization while preserving a natural situation. Obviously, merely being present during an emotionally relevant everyday event and recognizing its occurrence do not guarantee the kind of observation (of organism, e.g., physiological activation) that we wish to make. This point should be clear, given the above-mentioned flaws of self-observation methods used by Csikszentmihalyi and Csikszentmihalyi (1988), Levenson and Gottman (1985), and Reicherts and Perrez (1990), which transform the relevant events into reflexive reports about them. In order to keep a natural situation, we need to register elusive and even invisible domains of behavior without the use of complicated recording devices. To proceed as noninvasively as possible, we select as indicators of emotionalization or activation the physiological, psychomotor, and vocal aspects of real conver- sations that can be registered without (vocal) or with only minimal (physiological, psychomotor) interference with the ongoing situation. ${ }^{9}$

Verbal utterances with their vocal features as well as the concomitant physiological variable (peripheral blood volume changes) and changes of head movements are recorded with appropriate instruments. Each of these instruments (e.g., audiotape and videotape, photoplethysmographic recording devices, ultrasound sender and receivers) provides for minimally invasive recording. For a first impression of the records, see Figure 3.

Elaboration of the processing of psychomotor, physiological, and vocal concomitants of emotionalization are given in Altorfer et al. (2000), Jossen et al. (2000), and Zimmermann, Käsermann, Altorfer, Jossen, and Foppa (1998), respectively. The most important aspect of our joint database is that all data-sources are exactly coordinated with reference to a real-time dimension of communicative exchange. Furthermore, because we are interested in representing courses of activation as time series rather than as averages, the time dimension is both methodologically indispensable and substantially meaningful, as already elaborated above.

The second important point is to be able to register highly resolved data. On one hand, this claim is motivated by the fast (e.g., hormonal; see also Said, 1984) regulations of autonomic processes. On the other hand, it lies in the nature of conversation-that is, most speakers' contributions are quite short (average duration = about $2 \mathrm{sec}$ ), and a $1-\mathrm{Hz}$ density of resolution does not allow for deriving meaningful courses of activation. The exact solutions for a highly resolved registration of vocal (Zimmermann et al., 1998), psychomotor (Altorfer et al., 2000), and physiological (Jossen et al., 2000) expressions of activation changes are described elsewhere. Suffice it here to point out one characteristic of our physiological registration. Usually, peripheral blood volume changes registered by photoplethysmographic devices are used as an alternative to the more invasive registration of an ECG. But the information extracted from the former is the same as that extracted from the latter-namely, periods of heartbeats (IBIs). In contrast, we draw from the possibility of a vector analytic transformation of the signal, which yields a different but much more resolved kind of information about peripheral blood flow changes (see Jossen et al., 2000).

A third point in the transition from registration to measurement involves considering problems of how to deal with vast amounts of highly resolved multichannel data in order to finally be able to process the relevant part (but neither the irrelevant nor the noisy part) of observed variation.

The distinction between signal and noise. First, behavioral variation always consists of a signal and a noise part. The latter is created in principle by features of the recording device itself and by missing and/or faulty values resulting from the temporally less than proper functioning of recording devices. The result of such failures is nonmeaningful variation, which should not enter the 


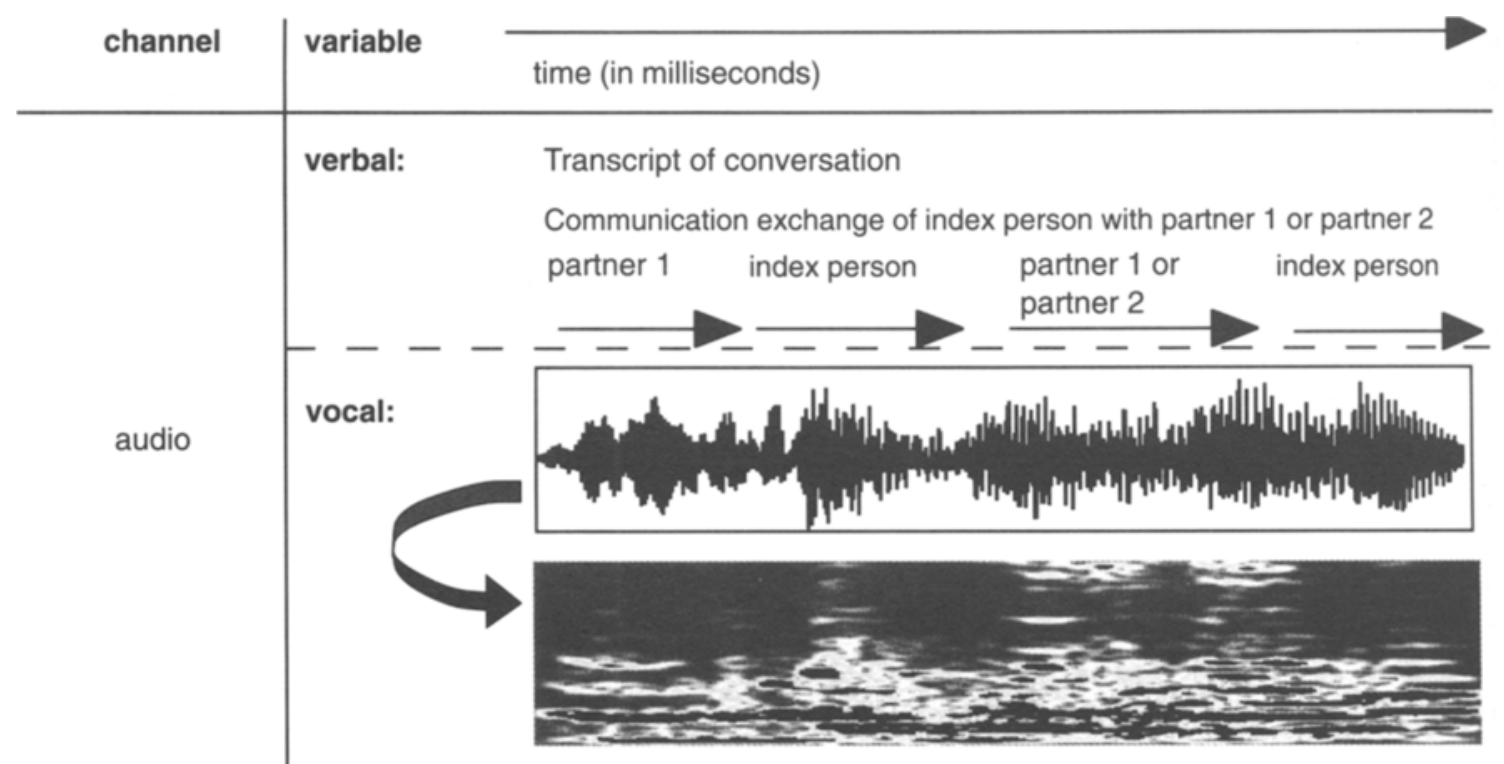

cf. Zimmermann et al., 1998

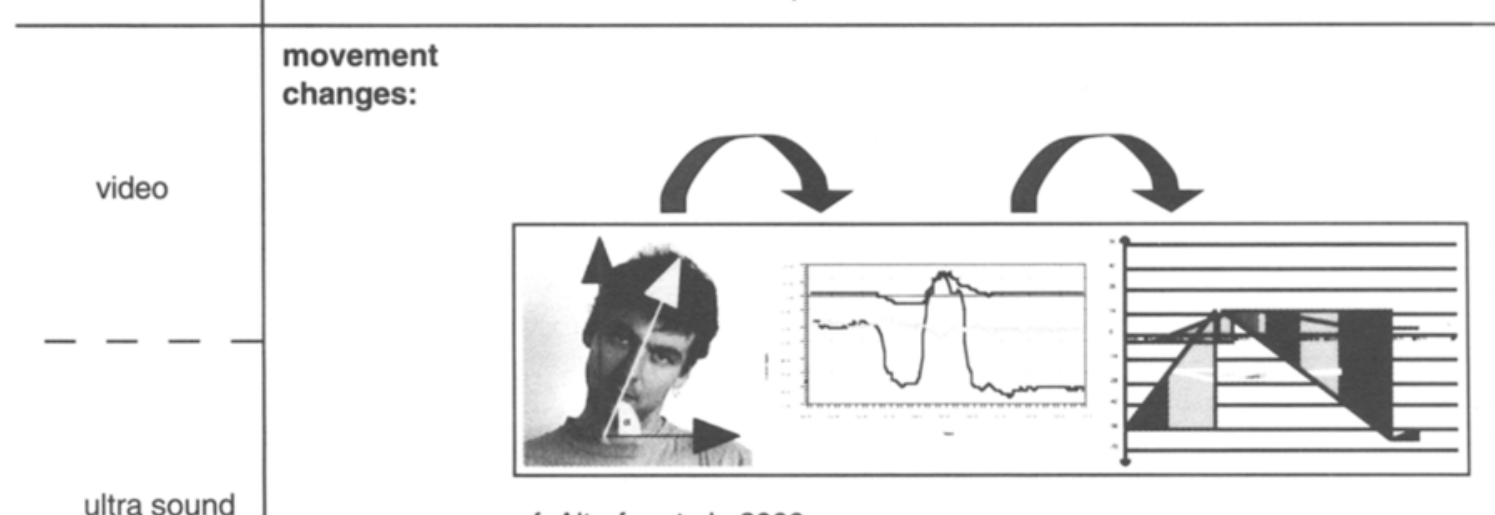

ultra sound

cf. Altorfer et al., 2000
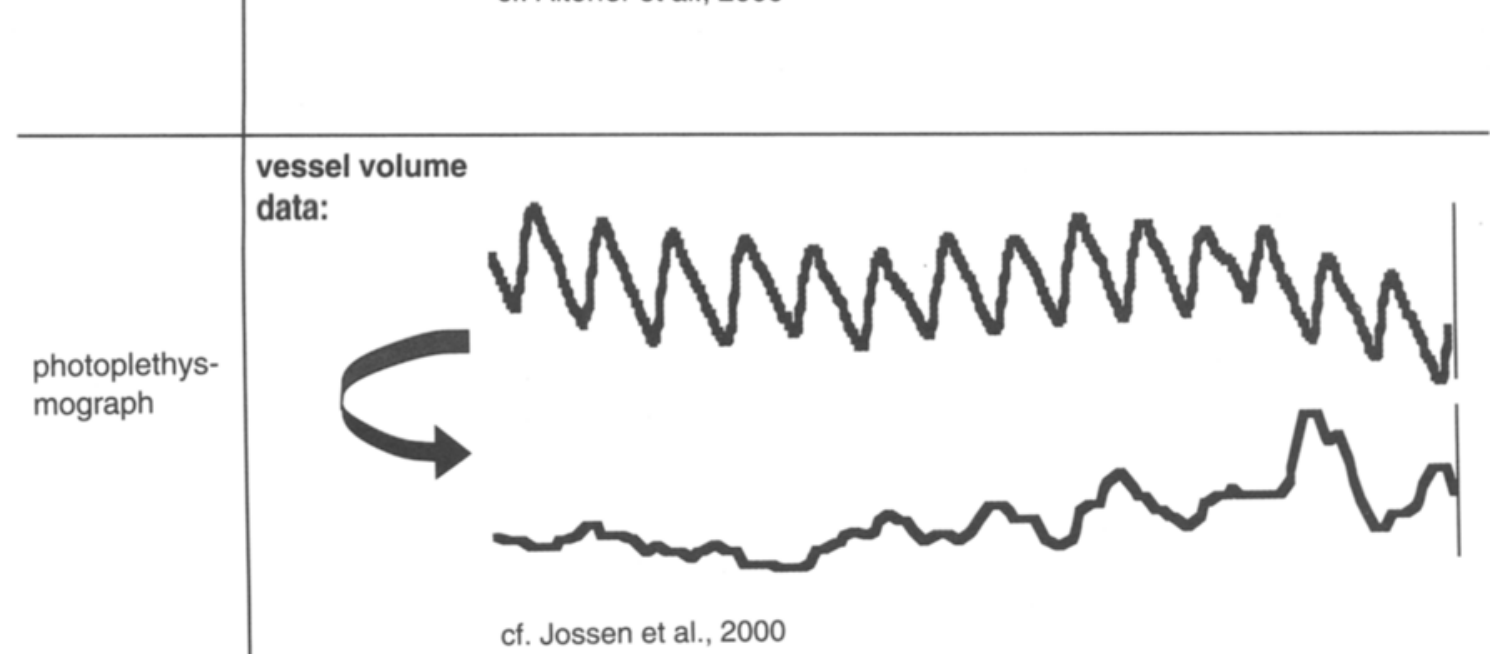

Figure 3. DATA BASE: Recording devices and records of the time-coordinated vocal, psychomotor, and physiological indicators of activation.

data arrays proper. Traditionally, this is achieved by trying to prevent the occurrence of noise through restricting an individual's behavior (e.g., by securing him/her to a dentist's chair in order to control artifacts). Yet such mea- sures obviously are interfering with the aim to preserve a natural situation. Therefore, we have to apply alternative means for distinguishing between signal and noise. That is, for each of our data channels, we developed computer- 
assisted procedures to detect "biologically unlikely events." A definition of these events is dependent on knowledge of the relevant behavioral domain and its biological limitations. Its realization lies in, for example, filtering out improbable frequency bands in vocal records (see Zimmermann et al., 1998) or noncontinuous jumpy head movements (Altorfer et al., 2000; see also Jossen et al., 2000, for a definition and the respective detection procedures of unlikely events in peripheral blood flow changes). Computer-based detection of noise as opposed to the prevention of its occurrence through behavioral restrictions has advantages. On one hand, one does not have to anticipate any possible source of noise; on the other hand, one does not unnecessarily restrict behavior that would not lead to disturbances anyway.

The distinction between irrelevant and relevant variation. Traditionally, the distinction between irrelevant and relevant parts of variation in the signal is achieved by the implementation of an experiment. The subsequent statistical processing of experimental data yields the (hopefully significant) differences of variation between baseline and intervention data. Yet doing research in natural situations prohibits exactly the experimental type of control of variation. Furthermore, what constitutes a rel- evant difference between standard and deviation courses of emotionalization cannot be primarily determined on a statistical basis (e.g., as a significant $t$ test value).

Our alternative of constructing "relevant effects" is contrastive analysis (CA) (Käsermann, 1995). It consists of the systematic organization of variation in the observed domains (e.g., communication and emotionalization). Basically, the organizing principle is simple: It derives from the linguistic concept of phonemic contrasts (e.g., Jakobson, Fant, \& Halle, 1951; Swadesh, 1934) and somewhat reverses the principles of doing experiments (see below). It is based on the assumption that meaningful contrasts (e.g., unobstructed vs. obstructed talk; or being in an emotionally neutral state vs. being emotionalized) in one domain covary with contrasting features in another domain (e.g., being in an emotionally neutral state vs. being emotionalized; smooth speaking vs. being interrupted). CA proper is the stepwise endeavor to detect specific covariation (Figure 4). It starts with the conceptual or empirical establishment of a contrast within a set of items in one domain (D1), thereby creating two subsets, and explores the other domain (D2) with regard to invariant features within both subsets, which are in contrast between the two subsets. The reconstruction of
STEPS:

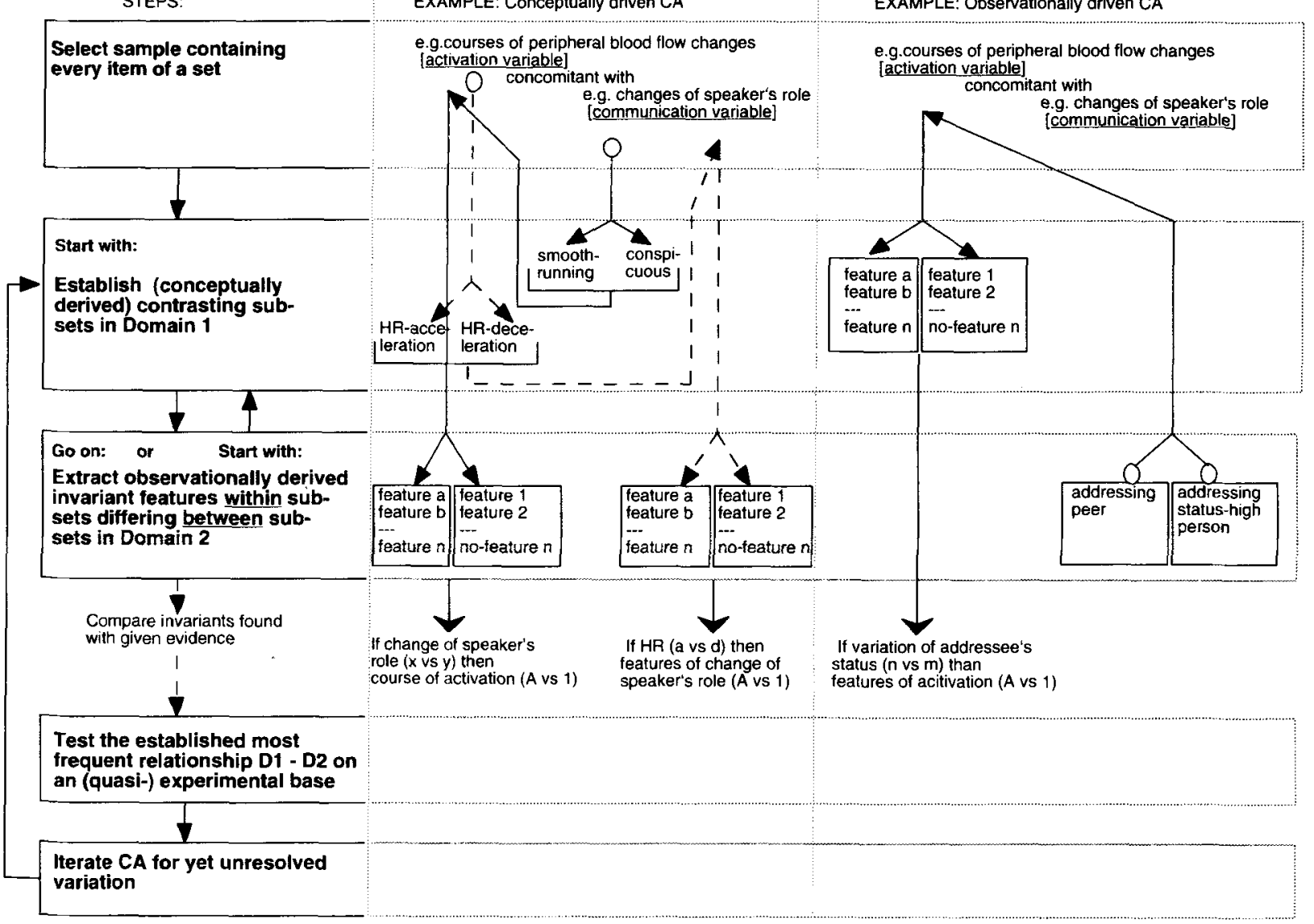

Figure 4. Contrastive analysis: Principle and examples. 
such invariants is the output of CA and can be considered either as test of a given hypothesis or as an empirical heuristic creating hypotheses (if contrasting values in $\mathrm{D} 1$, then contrasting values in D2), which then have to be tested within a (quasi-) experimental setup. CA can be iterated for first-, second-, $\ldots n$-level subsets until, ideally speaking, all observer variation is resolved. Driven by a conceptual contrast, CA gives answer to the question, Is the known meaningful D1 contrast meaningful also in the given D2? As an example, take as D1 contrast selfversus partner-attributed conversational silences and the respective contrasting invariant courses of activation in $\mathrm{D} 2$, which one hopefully is able to reconstruct. Driven by an empirical contrast, CA preliminarily gives answer to the question, Is, for a given D1, contrast a meaningful distinction in D2? As an example, take the observation of regular versus irregular courses of activation during utterances and the search for as many meaningful contrastive features in communication (e.g., speaking to a peer vs. speaking to a high-status person) tentatively explaining the physiological difference. Clearly, in both domains, CA may be driven by conceptually and empirically established contrasts. For example, a conceptual contrast with regard to the physiological domain would be the wellknown distinction between acceleration and deceleration of heart rate as meaningful for the type of reaction.

To illustrate a concept-driven CA, take the following example of processing a sample of observations (e.g., courses of activation concomitant with the change of speaker's role). According to our "theory" of emotionalization and already-existing evidence, it is conceptually meaningful to form two first-level subsets by a communicative criterion (e.g., smooth-running vs. in some way conspicuous change of speaker's role). Within and between each of these subsets, we comparatively determine the respective subset's invariant features of the concomitant courses of activation. These differences between the subsets are considered as the specific "relevant effect" predicted by the criterion. If the effect consists of physiological features similar to those found in comparable analyses, the result counts as an affirmation of the hypothesis. If the effect consists of physiologically dissimilar features, a quasi-experimental replication is set up. If successful, the systematic differences between physiological effects in different samples have to be processed further. However, tentative explanations may rest on physiological rather than psychological knowledge. ${ }^{10}$ In any case, this example shows that CA can be used to test hypotheses as well as to heuristically detect potentially explanatory features.

It should be pointed out that the CA somehow reverses the experimental logic. What we have to start with is variation (e.g., on the organism and communicative dimension) and the assumption that there is systematic covariation between the domains. With regard to contrasting subsets (formed on the basis of a hypothetically relevant, e.g., communication criterion), within and between comparisons of items of the subset enable the extracting of the invariant features (of courses of activation) charac- teristic of these subsets. They can be conceived of as the significant effect of (the hypothesized) conditions systematically controlling the observed variation. By a subsequent quasi-experimental procedure, empirically derived relationships can be tested. In the case of a CA based on already-existing evidence, however, the output of a $\mathrm{CA}$ counts as a test of a hypothesis. As already stated, the underlying rationale is the assumption that any variation that is not due to noise is potentially meaningful with regard to yet unknown conditions. Possible variation, therefore, must not be restricted or controlled as a disturbance variable but instead must be resolved with reference to these conditions that control its occurrence.

We applied CA to conversations of healthy and schizophrenic individuals with their partners. We (Käsermann \& Altorfer, 1994) found that the critical event of a conversational silence has a very different effect in the two diagnostic categories. Its function as a stressor depends on who speaks to whom, on how knowledge is distributed between the participants, and on whether, for the index person, it remains ambiguous which one of the two is responsible for an occurring silence. So, a specific index person (but not another one) interprets a silence as a stressor and reacts with stress only if certain combinations of these conditions are met. In combination with TA (see above), CA can be considered as a powerful instrument for finding and testing hypotheses in data from natural situations.

Analyzing time courses of activation in natural conversation. The process of defining standard and deviation courses of activation changes over time can be understood as an endeavor to build an inventory of classes of equivalent items. Items of such classes are identifiable wherever they show up. In the special case of a singlecourse approach, the identification is supported by the application of TA. In other words, the intermediary step of defining standard-deviation relations yields as its product not "effects" in a narrow experimental sense but classes of meaningful courses or single courses, which differ from each other significantly. Freed from the controlled binding of an eliciting independent variable, these types of courses can be conceived of as the consequences of some antecedents, but they can also be conceived of as antecedents of some subsequent change. Furthermore, they can become the targets of modification and/or reflection. In our view, therefore, any given value of emotionalization may play a triple role: First, it can be conceived of as an indicator of (elicited) activation changes. Second, these changes may function as determinants of the further course of conversation. Third, they may become the target of modification and/or reflection not only for the index person but also his/her conversational partners. To illustrate these different facets, consider the meaningful courses of a stress reaction. If you are able to identify its occurrence independently of other levels of data or information, you have in principle three routes of investigation:

1. The heuristic use of known meaningful courses of variation in resolving their antecedent conditions: For any known pattern of activation (e.g., a stress reaction), you 
can test whether or not it occurs after that spontaneously occurring critical (communicative, organism) event that you are actually interested in. To the yet unresolved variation of a stress reaction, you then apply contrastive analysis with the aim of forming hypotheses about yet unknown critical events and additional conditions responsible for the occurrence of that stress reaction. These hypotheses may encompass communicative violations, such as emotionally overinvolved statements or verbal threads. Furthermore, they may make explicit additional conditions, such as features of people, places, and situations, under which these critical events might be interpreted as stressors. Such additional hypotheses may then be tested within a quasi-experimental setting - that is, within a (systematically varied) conversation in which an informed person inserts a communicatively critical behavior into an otherwise natural conversation (Käsermann \& Altorfer, 1991). If a stress reaction can be systematically induced by such a procedure, you have completed your psychological knowledge about stressors. The same holds true for investigations of organism variables.

2. The consequences of stress reactions: If a stress reaction takes place, one can ask whether its occurrence has any systematic consequences not only on the behavior of the partner but also on the behavior of the index person himself or herself (Käsermann et al., 1997, 1998). For instance, an observable stress reaction may induce a partner to verbally distance or apologize for hurting the index person, the latter being an emphatic reaction. Or it may induce the index person himself or herself to cope verbally (e.g., by evasive communicative behavior, or by actually moving out of the field). Each type of one's own or the other's reaction may again influence the course of activation. Reactions ameliorating a given high level of activation can be considered as locally successful for the index person. Gathering knowledge about the effect of such coping is obviously important for therapeutic interventions.

3. Stress reactions as a target of modification and/or reflection: Each individual taking part in a conversation may become aware of the relationship between a stress reaction, its antecedents, the consequent coping and what these mean altogether for the further course of activation. With regard to the index person, experiencing or not experiencing a relief from the stress reaction, when reacting (e.g., communicatively) to a given stressor, creates an instrumental learning situation. Investigations of this learning paradigm may provide insights into the psychological functioning of types of individuals. For instance, it seems to be the case that schizophrenics do not exploit information about stress-related events in the same way as do healthy persons (Käsermann et al., 1998). There is yet another implication of becoming aware of oneself as a person exerting stressors or experiencing stress. This is the growing possibility of using the occurrence or nonoccurrence of the respective behaviors strategically. That is, you can politely prevent the emitting of a stressor if you want to be nice to someone, but you also can emit it intentionally in order to be nasty. Or you can prevent your stress reaction from showing up by controlling your expression, or, conversely, you can put on the show of being stressed if you know that this would be instrumental in manipulating your partner into a consoling reaction. In the case of such strategic uses of stress reaction, one would expect a dissociation between expressive (e.g., vocal and psychomotor) and physiological signs of stress.

\section{Summary and Conclusions}

To sum up, our research addresses the problem of investigating emotionalization when it takes place during social interaction and natural conversation. We investigated the organism indicator of emotionalization in communicative interaction, its communicative antecedents, and its experiential and its communicative consequences. Our intention to preserve as natural a research situation as possible led us to develop a set of semiautomated methodologies for the identification of "biologically unlikely events," "relevant effects," and standard and deviation templates. These methodologies allow for a programguided processing of vast amounts of observational data in a reasonable time. They rest on some conceptual developments. Essential for the identification of elicitors of emotionalization is the conceprion of conversation as a rule-governed event and its formalization in the minimal model of communicative exchange. Furthermore, the principle of standard and deviation forms a base for a conceptualization of emotionalization, which, with the help of contrastive analysis, allows for the identification of its occurrence independent of any eliciting conditions. The model and the principle form the conceptual basis for the assumption of meaningful variation, which, resolved by systematic contrastive analysis of standard and deviation courses of behavior, yields hypotheses to be tested by quasi-experimental procedures. The implementation of these ideas is elaborated further with regard to physiology (Jossen et al., 2000) and head movement (Altorfer et al., 2000). The preliminary steps of the analysis of vocal aspects of behavior are also documented (Zimmermann et al., 1998). In addition to theoretical and methodological considerations, some fields of application are outlined.

\section{REFERENCES}

Altorfer, A., Jossen, S., Würmle, O., Käsermann, M. L., Foppa, K., \& ZimmermanN, H. (2000). Measurement and meaning of head movements in everyday face-to-face communicative interaction. $\mathrm{Be}$ havior Research Methods, Instruments, \& Computers, 32, 17-32.

Berscheid, E. (1983). Emotion. In H. H. Kelley, E. Berscheid, A. Christensen, J. H. Harvey, T. L. Haston, G. Levinger, E. McClintock, L. A. Peplau, \& D. R. Peterson (Eds.), Close relationships (pp. 110-169). New York: Plenum.

Blonder, L. X., Burns, A. F., Bowers, D., Moore, R. W., \& Heilman, K. M. (1993). Right hemisphere facial expressivity during natural conversation. Brain \& Cognition, 21, 44-56.

Csikszentmihalyi, M., \& Csikszentmihalyi, I. S. (1988). Introduction to IV: The measurement of flow in everyday life. In M. Csikszentmihalyi \& I. S. Csikszentmihalyi (Eds.), Optimal experience: Psychological studies of flow in consciousness (pp. 251-265). New York: Cambridge University Press. 
Denham, S. A. (1993). Maternal emotional responsiveness and toddlers' social-emotional competence. Journal of Child Psychology \& Psychiatry \& Allied Disciplines, 34, 715-728.

Denham, S. A., \& Couchoud, E. A. (1990a). Young preschoolers' ability to identify emotions in equivocal situations. Child Study Journal, 20, 153-169.

Denham, S. A., \& Couchoud, E. A. (1990b). Young preschoolers' understanding of emotions. Child Study Journal, 20, 171-192.

Donne, J. A., West K. L., Goldstein, M. J., Rodnick, E. H., \& Jones, J. E. (1981). Parental communication deviance and affective style: Prediction of subsequent schizophrenia spectrum disorders in vulnerable adolescents. Archives of General Psychiatry, 38, 679-685.

EisenberG, N., Fabes, R. A., Karbon, M., Murphy, B. C., WosinSki, M., Polazzi, L., Carlo, G., \& Juhnke, C. (1996). The relations of children's dispositional prosocial behavior to emotionality, regulation and social functioning. Child Development, 67, 974-992.

Ekman, P., \& Friesen W. V. (1978). Facial action coding system. Palo Alto: Consulting Psychologists Press.

Ekman, P., Friesen, W. V., \& Ellsworth, P. (1972). Emotion in the human face: Guidelines for research and an integration of findings. New York: Pergamon.

EPSTEIN, S., \& FENZ, W. D. (1965). Steepness of approach and avoidant gradients in humans as a function of experience: Theory and experiment. Journal of Experimental Psychology, 70, 1-12.

Fabes, R. A., Eisenberg, N., Karbon, M., Troyer, D., \& Switzer, G. (1994). The relations of children's emotion regulation to their vicarious emotional responses and comforting behaviors. Child Development, 65, 1678-1693.

FoPPA, K. (1990). Topic progression and intention. In I. Markovà \& K. Foppa (Eds.), The dynamics of dialogue (pp. 178-200). New York: Harvester Wheatsheaf.

FoPPA, K. (1999). Das vergessene Gedächtnis: Über rezeptives Erinnern [The forgotten memory: On remembering receptively]. Zeitschrift für Psychologie, 207, 149-172.

GARFINKEL, H. (1963). A conception of and experiments with "trust" as a condition of stable concerted actions. In O. J. Harvey (Ed.), Motivation and social interaction: Cognitive determinants (pp. 187238). New York: Ronald.

GARFINKEL, H. (1967). Studies in ethnomethodology. Englewood Cliffs, NJ: Prentice Hall.

Glaser, R., Rice, J., Sheridan, J., Fertel, R., Stout, J., Speicher, C., Pinsky, D., Kotur, M., Post, A., Beck, M., \& Kiecolt-Glaser, J. [K.] (1987). Stress-related immune suppression: Health implications. Brain, Behavior, \& Immunity, 1, 7-20.

Goffman, E. (1981). Forms of talk. Philadelphia: University of Pennsylvania Press.

Gottman, J. M., \& Levenson, R. W. (1992). Marital processes predictive of later dissolution: Behavior, physiology, and health. Interpersonal Relations \& Group Processes, 63, 221-233.

GRICE, H. P. (1975). Logic and conversation. In P. Cole \& L. Morgan (Eds.), Syntax and semantics (pp. 41-58). New York: Academic Press.

HERITAGE, J. (1989). Current developments in conversation analysis. In D. Roger \& P. Bull (Eds.), Conversation: An interdisciplinary perspective (pp. 21-47). Clevedon: Multilingual Matters.

HerrmanN, T., \& Grabowski, J. (1994). Sprechen: Psychologie der Sprachproduktion [Speaking. Psychology of speech production]. Heidelberg: Spektrum Akademischer Verlag.

Heydrick, W., Neubauer, F., Petöft, J. S., \& Sözer, E. (1989). Connexity and coherence: Analysis of text and discourse. Berlin: de Gruyter.

Hughes, C., Uhlmann, C., \& Pennebaker, J. W. (1994). The body's response to processing emotional trauma: Linking verbal text with autonomic activity. Journal of Personality, 62, 565-585.

JakobSOn, R., Fant, C. G. M., \& Halle, M. (1951). Preliminaries to speech analysis: The distinctive features and their correlates. Cambridge, MA: MIT Press.

Jossen, S., Käsermann, M.-L., Altorfer, A., Foppa, K., ZimmerMANN, H., \& HirshrRunNer, H.-P. (2000). The study of emotional processes in communication: II. Peripheral blood flow as an indicator of activation. Behavior Research Methods, Instruments, \& Computers, 32, 47-55.

KäSERMANN, M.-L. (1989). The assumption of functionality of com- municative acts as a tool for investigating cognition in schizophrenia. Communication \& Cognition, 22, 157-168.

KäsermanN, M.-L. (1995). Emotion im Gespräch: Auslösung und Wirkung [Emotion in dialogue: Elicitation and effect]. Bern: Hans Huber.

KäSERMANN, M.-L. (1998). Regelverletzungen und Emotionalisierung. Auftreten und kommunikationsabhängige Regulation bei Gesunden und Schizophrenen [Rule violation and emotionalization: Occurrence and dialogue-dependent regulation in healthy and schizophrenic individuals]. In W. Hacker, H. P. Klein, \& M. G. Bleschke (Eds.), Zukunft gestalten [Shaping future] (41. Kongress der Deutschen Gesellschaft für Psychologie. Abstract discs $1 \&$ 2). Munich, LMU, H. P. Klein.

KäSERMANN, M.-L., \& Altorfer, A. (1989). Family discourse: physiological correlates of different degrees of stress. British Journal of Psychiatry, 155(Suppl. 5), 136-143.

KäSERMANN, M.-L. \& AltoRFer, A. (1991). Was uns in Gesprächen aufregt ... Störendes kommunikatives Verhalten und seine Wirkung auf den Gesprächspartner [Initiation in conversation ... Disturbing communicative behavior and its effect on one's partner]. In K. Grawe, R. Hänni, N. Semmer, \& F. Tschan (Eds.), Über die richtige Art Psychologie zu betreiben (pp. 343-356). Göttingen: Hogrefe.

KäsermanN, M.-L., \& Altorfer, A. (1994). Communicative stress and coping in schizophrenic and healthy persons. In A. Beigel, J. J. Lopez Ibor, \& J. A. Costas e Silva (Eds.), Past, present and future in psychiatry: IX World Congress of Psychiatry (pp. 451-455). Singapore: World Scientific.

Käsermann, M.-L., Altorfer, A., \& Jossen, S. (1997). Communicative stressors and protectors and the autonomic response in schizophrenic and healthy individuals. European Psychiatry, 12(Suppl. 2), $109 \mathrm{~s}$.

KäSERmanN, M.-L., Altorfer, A., \& Jossen, S. (1998). The effect of stressful and protective communicative events on the autonomic response in schizophrenic and healthy persons. International Clinical Psychopharmacology, 13(Suppl. 1), S103-S105.

KiECOLT-GlaSER, J. [K.] (1992). Acute psychological stressors and shortterm immune changes: What, why, for whom, and to what extent? Psychosomatic Medicine, 54, 680-685.

Kiecolt-Glaser, J. [K.], \& Glaser, R. (1988). Methodological issues in behavioral immunology research with humans. Brain, Behavior, \& Immunity, 2, 67-78.

Kiecolt-Glaser, J. K., \& Glaser, R. (1991). Stress and immune function in humans. In R. Ader, D. I. Felten, \& N. Cohen (Eds.), Psychoneuroimmunology (pp. 849-867). New York: Academic Press.

Lang, P. J., Bradley, M. M., \& CuthberT, B. N. (1990). Emotion, attention, and the startle reflex. Psychological Review, 97, 377-395.

LeFF, J., \& VAUGHN, C. (1985). Expressed emotion in families. New York: Guilford.

Levenson, R. W., Carstensen, L. L., Friesen, W. V., \& Ekman, P. (1991). Emotion, physiology, and expression in old age. Psychology \& Aging, 6, 28-35.

Levenson, R. W., Carstensen, L. L., \& Gottman, J. M. (1994). The influence of age and gender on affect, physiology, and their interrelations: A study of long-term marriages. Interpersonal Relations \& Group Processes, 67, 56-68.

Levenson, R. W., \& GotTman, J. M. (1983). Marital interaction: Physiological linkage and affective exchange. Journal of Personality \& Social Psychology, 45, 587-597.

Levenson, R. W., \& Gottman, J. M. (1985). Physiological and affective predictors of change in relationship satisfaction. Journal of Personality \& Social Psychology, 49, 85-94.

MANDLER, G. (1975). Mind and emotion. New York: Wiley.

MCCANN, C. D., \& HyGGINS, E. T. (1988). Motivation and affect in interpersonal relations: The role of personal orientations and discrepancies. In L. Donohew, H. E. Sypher, \& E. T. Higgins (Eds.), Communication, social cognition, and affect (pp. 53-79). Hillsdale NJ: Erlbaum.

Miller, G. A. (1999). On knowing a word. Annual Review of Psychology, 50, 1-19.

Motley, M. T., \& CAmden, C. T. (1988). Facial expression of emotion: A comparison of posed expressions vs. spontaneous expressions in an interpersonal communication setting. Western Journal of Speech Communication, 52, 1-22.

Pennebaker, J. W., Hughes, C. F., \& O'Heeron, R. C. (1987). The 
psychophysiology of confession: Linking inhibitory and psychosomatic processes. Journal of Personality \& Social Psychology, 52, 781-793.

Pennebaker, J. W., \& Uhlmann, C. (1994). Direct linking of autonomic activity with typed text: The CARMEN machine. Behavior Research Methods. Instruments, \& Computers, 26, 28-31.

Porges, S. W. (1992). Vagal tone: A physiological marker of stress vulnerability. Pediatrics, 90, 498-504.

Prinz, W. (1990). Unwillkürliche Aufmerksamkeit [Automatic attention]. In C. Meinecke \& L. Kehrer (Eds.), Bielefelder Beiträge zur Kognitionspsychologie (pp. 49-75). Göttingen: Verlag für Psychologie.

Reicherts, M., \& Perrez, M. (1990). Einflüsse von Repression und Sensitization auf die Selbstbeobachtung der Belastungsverarbeitung [Repression and sensitization as factors influencing self-observation during coping with stress]. Zeitschrift für Klinische Psychologie, Psychopathologie und Psychotherapie, 38, 324-333.

Sacks, H., Schegloff, E. A., \& Jefferson, G. (1974). A simplest systematics for the organization of turn-taking for conversation. Language, 50, 696-735.

Saenger-Alt, C., Steiner-Krause, E., Wagner, G., \& Krause, R. (1989). Mimisches Verhalten psychosomatischer Patienten [Mimic behavior in patients with psychosomatic disturbances]. Zeitschrift für klinische Psychologie, 18, 243-256.

SAID, S. I. (1984). Vasoactive intestinal polypeptide VIP: Current status. Peptides, 5, 143-150.

Schedlowski, M., Jacobs, R., Stratman, G., Richter, S., HädiCke, A., Tewes, U., Wagner, T. O. F., \& SChmidt, R. E. (1993). Changes of natural killer cells during acute psychological stress. Journal of Clinical Immunologv, 13, 119-126.

Schegloff, E. A., \& SaCkS, H. (1973). Opening up closings. Semiotica, 7, 289-327.

SCHERER, K. R. (1988). Criteria for emotion-antecedent appraisal: A review. In V. Hamilton, G. H. Bower, \& N. H. Frijda (Eds.), Cognitive perspectives on emotion and motivation (pp. 89-126). Dordrecht: Kluwer.

SCHERER, K. R. (1990). Theorien und aktuelle Probleme der Emotionspsychologie [Theories and questions of current interest in the psychology of emotion]. In K. R. Scherer (Eds.), Psychologie der Emotion (pp. 1-38). Göttingen: Hogrefe.

Scherer, K. R., \& TANnenbaum, P. H. (1986). Emotional experiences in everyday life: A survey approach. Motivation \& Emotion, 10, 295-314.

Scherer, K. R., WAllbotT, H. G., Matsumoto, D., \& KuDOH, T. (1988) Emotional experience in cultural context: A comparison between Europe, Japan and the United States. In K. R. Scherer (Ed.), Facets of emotion: Recent research (pp. 5-30). Hillsdale, NJ: Erlbaum.

SWADESH, M. (1934). The phonemic principle. Language, 10, 117-129.

TANNEN, D. (1981). New York Jewish conversation style. International Journal of Sociology of Language, 30, 133-149.

VAUGHN, C., \& LEFF, J. (1976). The measurement of expressed emotion in the families of psychiatric patients. British Journal of Social \& Clinical Psychology, 15, 157-165.

Zimmermann, H., Käsermann, M.-L., Altorfer, A., Jossen, S., \& FOPPA, K. (1998). Measurement and analysis of vocal aspects of communicative interaction [Abstract]. In Measuring behavior '98: 2nd International Conference on Methods and Techniques in Behavioral Research (p. 305). Groningen: Noldus Information Technology.

\section{NOTES}

1. In most research pertinent to ours (e.g., Gottman \& Levenson, 1992; Pennebaker et al., 1987), the problem of elicitors is tackled in a different way. Their subjects are instructed to talk about traumatic events or conflicts. Thus, there is no need for an identification of events presumably eliciting emotional processes. However, we are interested in elicitors as they naturally occur in social and communicative situations rather than in oppressing our ideas about elicitors on subjects even if these ideas are adequate. What we are looking for, therefore, is a somewhat content-free principle for the identification of elicitors.
2. Ultimately, the problem of the definition of meaning is a philosophical one. It does not lie in our intention or competence to answer this notoriously difficult question. What we propose with our negativeexclusive definition is an empirically applicable principle that does not imply a researcher's claim to know better than the speaker himself/herself what he/she really wants to say.

3. Possibly, the basic A1-B1-A2 unit implies some ideal assumptions about communicative exchange, the first being that it is default for a participant to expect a partner not to misinterpret him or her. Obviously, this naive assumption does not hold true for some forms of strategic communication; however, since strategic communication, in our opinion, is a very special case of everyday communication, it has to be treated as such. The second assumption is that whenever in $\mathrm{Bl}$ there occurs any form of non- or misunderstanding, A will correct it. This is clearly not the case because there are factors, such as lack of interest or boldness, that very well may prevent the occurrence of a correction.

4. For example, the progress of therapeutic work can be assumed to rest on the working through and relinquishing of specific elicitors of (outdated) emotionalization.

5 . The concept of neutrality is not very often spelled out in research about emotional processes (for exceptions, see Denham, 1993; Levenson \& Gottman, 1985, p. 86). Admittedly, it is also an indeterminate concept, which for us primarily implies the absence of any ongoing emotionalization. However, the fact of a very swift functioning autonomic regulation seems to legitimize the assumption of the existence of such a standard or default course of neutral activation that, to our mind, is also implied in the concept of homeostasis (see also Porges, 1992).

6. With the application of the standard-deviation principle to conceptualizing emotional processes, we do not intend to propose a fully fledged theory of emotion. Rather, what we are interested in is the application of a psychologically plausible concept to the solution of the given empirical problem of investigating ongoing emotional processes in everyday situations. Speculatively, we would say that the proposed concepts of activation neutrality and deviations from it are somewhat orthogonal to concepts connected with theories of distinct emotions. That is, we think it is possible to conceive of a sustained happy or sad mood as that neutral (homeostatic) condition against which actual deviations create an emotionalization.

7. While it is not uncommon in research pertinent to ours (see, e.g., Levenson et al., 1994) to operate with relaxation periods as baseline data, we have been criticized for selecting them as a standard course of activation because of the risk of misinterpreting Type II errors as relevant effects. Although we share this reservation in principle, there are two mitigating points that have to be taken into consideration. First, the concept of standard and deviation has to be understood as a theoretical claim, which states the basic relational character of the relevant event and leaves open how exactly it has to be substantiated. It is up to the researcher to determine what constitutes an appropriate standard with regard to a given situation. Second, we agree that the most plausible standard situation in conversation would be the activation pattern during talk about neutral topics. However, since it is impossible to control the topics of talk in natural conversation, one often does not find episodes that are topically neutral. Luckily, with regard to conversations that do have neutral passages, we observe that the course of activation during these episodes equals the course of activation during relaxation (see note 5 about homeostasis).

8 . That is, both procedures allow for the detection of all courses of activation that deviate from or are congruent with standard courses. On one hand, the subsequent distribution of standard and deviation courses to situations in which their occurrence is or is not expected is instrumental for testing given hypotheses. On the other hand, the exploration of items in the nonexpected categories (standard course in critical situation, deviation course in neutral situation) helps developing hypotheses about additional conditions controlling variation.

9. The reason we dispense with the registration of facial expressions of emotion is threefold. First, the most often used method, FACS (Ekman \& Friesen, 1978), can be applied only to a face, which invariably (but not very naturally) is posed parallel to the camera. Second, our ap- 
proach to emotional processes is not rooted in the assumption of distinct emotion, so we are naturally not primarily interested in identifying them. Third, even if we were believers in distinct physiognomic patterns of emotion (in pertinent research, usually posed by instructed actors), we could not but acknowledge some critical empirical evidence. It states that it is hard to identify emotions in faces of persons suffering from brain lesions (Blonder, Burns, Bowers, Moore, \& Hellman, 1993) and psychosomatic conditions (Saenger-Alt, Steiner-Krause, Wagner, \& Krause, 1989), but also in healthy individuals if emotions occur spontaneously during natural conversation (Motley \& Camden, 1988).

10. CA can be applied to gaining additional knowledge about physiological variation. It is possible to assume that its yet unresolved varia- tion reflects the systematic influence of factors other than the heartbeat. One of theses factors is respiratory activity, which under stress may become hasty and flat; another is muscle tension, which may augment and affect the vessels; a third one is hormonal drain and its intricate, though widely unknown, influences on vessel volume (Kiecolt-Glaser, 1992). The question as to whether these and other factors indeed have a systematic influence on the shape of activation courses can be resolved with the same iterative processing described above.

(Manuscript received December 18, 1998 ; revision accepted for publication November $2,1999$. 